\title{
The Sources and Impact of Stress of Teachers on the Performance of Learners: the View Point of the High School Teachers in Khomas Region in Namibia
}

\author{
Stewart Kaupa \\ Namibia University of Science and Technology, Windhoek-Namibia
}

\begin{tabular}{|c|c|}
\hline & ABSTRACT \\
\hline $\begin{array}{l}2016 \text { Research Leap/Inovatus Services Ltd. } \\
\text { All rights reserved. } \\
\text { DOI: } 10.18775 / \text { jibrm.1849-8558.2015.54.3002 } \\
\text { URL: } \underline{\text { http://dx.doi.org/10.18775/jibrm.1849- }} \\
\text { 8558.2015.54.3002 }\end{array}$ & $\begin{array}{l}\text { Excessive pressure emanating from economic recession, heavy competition, modern and rapid } \\
\text { technological changes, coupled with demands of jobs have emerged as key drivers of work-related } \\
\text { stress amongst employees. Stress exists in all phases of our life and if not tactfully handled it can } \\
\text { lead one's mental state to depression. In the workplace, it can affect performance of employees, thus } \\
\text { affect the productivity of an organisation. It is against this background that this study aimed at } \\
\text { investigating the relationship between work-related stress of high teachers and the performance of } \\
\text { learners in high schools in the Khomas Region in Namibia. } 100 \text { teachers were sampled using }\end{array}$ \\
\hline $\begin{array}{l}\text { Keywords: } \\
\text { Work stress, Management, Stressors, teachers, } \\
\text { Khomas Region, Namibia. }\end{array}$ & $\begin{array}{l}\text { qualitative and quantitative methods were used. The findings from the study revealed that work } \\
\text { stress does exist in amongst high school teachers due to the stressful nature of their work. The key } \\
\text { drivers of work stress amongst high school teachers were noted to be; the shortage of staff in } \\
\text { schools, lack of resources; workload; poor remuneration and poor working conditions, resulting in, } \\
\text { absenteeism and turnover of teachers, temper outbursts and suicidal thoughts amongst the teachers } \\
\text { all of these having a negative impact on the performance of teachers. Based on these findings the } \\
\text { study recommends the Ministry of Education to introduce work stress management which can take } \\
\text { the form of workshops and training to assist teachers to better deal with work-related stress which } \\
\text { negatively impacts on their performance and that of learners. The key limitation of the study was } \\
\text { that some respondents were reluctant to reveal the extent of the problem amongst them as they felt } \\
\text { that in any case the ministry will not do anything about their problems. }\end{array}$ \\
\hline
\end{tabular}

\section{Introduction}

Teachers are key social agents that help learners to dream and reach their highest potential and develop into responsible citizens. Teachers play a critical role in the lives of children, but over the years teaching has become increasingly stressful. Today teaching is one of most stressful occupation behind police officers. Research has shown that teacher stress impacts teacher's health and well-being, work attitudes and turnover but very little is known as to how this teacher stress impacts on the performance of learners in high schools in Namibia. This paper examines the sources and impact of teacher stress on the performance of learners in high schools.

The theory of stress management in life sciences was introduced by Hans Selye in 1936. Stress among teachers is always discussed by the society but very little research has been carried out in Namibia to establish the sources as well as the impact of this on the performance of learners. According to Levenson and Roberts (2001) the occupation of teachers is one of the most stressful occupations in America and that, work stress can reverberate through all aspects of life.

Work stress remains of profuse worry to organisations including the public sector such as the Ministry of Education and its teachers, staffs, and other stakeholders. Work stress is a serious problem in many organisations and has been cited as a major contributor to the low productivity of many organisations as well as the main cause of early retirement for many employees (Varca, 1999; Ornelas \& Kleiner 2003; Cooper \& Cartwright, 1994). High school teachers work with the public from diverse background and if they are stressed, their schools as well as the learners that are placed under their care are negatively affected as they do not perform as expected. Work stress reduces or affects the performances of individuals at work as well as at their homes since people cannot be completely separated from their work and personal lives (Bowin \& Harvey, 2001). Stressful events raise blood pressure and affect the heart. Cooper, Cooper, and Eaker, (1988) argue that employees experience coronary artery disease because of work stress and work stress is believed to be correlated to heart attacks, hypertension and other diseases.

\section{Literature Review}

\subsection{Understanding Work related Stress}

In a contemporary society, it is unbelievable to think of people without stress or work stress. This is so because people spend most of their life at work. Subsequently, everyone in the workplace from a lower level employee up to the managers spends most of their time thinking about work and its activities. Henceforth, it will be true to say that the main facet pushing people into stress is the working life. Although Rees and Redfern (2000), argue that there is no collectively accepted 
definition of the term stress, Ornelas and Kleiner (2003), maintain that stress is the by-product of present life that result from our determinations of trying to balance the demands of the workplace and of family life. Robbins (2001) argues that stress is a dynamic condition in which an individual is confronted with opportunities, constraints and demands related to what he or she desires and aimed at the perceived outcome to be both undefined and important.

Similarly, Van Heerden (2005) defines stress as people's reaction to excessive pressure. It is not a disease, but if stress is excessive and goes on for some time, it can lead to mental and physical health problems, for example, depression, nervous breakdown and heart disease. Ornelas and Kleiner (2003) on the other hand argue that stress is a by-product of modern life that results from our efforts of trying to balance the demands of the workplace and of family life. Tehrani (2002) argues that work stress is instigated by uncaring organisational culture, bullying, lack of involvement in decision-making, poor communication between managers and employees, and harassment, continual or sudden change, insufficient resources, conflicting priorities and lack of challenges. The focus of this study was on work related stress because, work stress has become an increasingly common negative consequence of today's active life.

Albrecht, (2010), acknowledges four types of stress that befall people at the workplaces and these are: time stress, anticipatory stress, situational stress and encounter stress:

Time Stress: Albrecht, (2010), relates this type of stress to a situation where persons lack enough time to finish all of their allocated duties and that such employees or persons struggle and are troubled by the number of things they are supposed to do. This is supported by Fried (2008), who asserts that workers under time stress fear about deadlines and most of the time hasten to avoid being late which compromises on the quality of the product most of the time.

Anticipatory Stress: This defines the stress that employees go through concerning their future especially when they worry about the fact that something might go wrong in the near future. According to Albrecht, (2010), such stress is generally concentrated on a particular incidence within the organisation, which directly impacts the employees and in most cases these employees do not have control or influence over such things. This would be instances such as waiting for the outcome of the matric results in high school.

Situational Stress: This is believed to transpire when individuals are in a threatening situation over which they have no control. Albrecht, (2010), asserts that, in many occasions, this happens due to a crisis that transpires in the organisation and that situations of this nature may comprise of conflict of interest, loss of acceptance or change in status in an individual's group. Additionally, when people make enormous mistakes in front of their managers or their colleagues, it makes them stressed (Albrecht, 2010).

Encounter Stress: People get stressed when they are nervous about intermingling with a particular group of individuals or a particular person (Albrecht, 2010). This aforementioned author further states that this type of stress frequently occurs in a condition where workers interact with clients or customers who may be in some form of distress. It is therefore evident that, the stressful nature of the teaching profession, along with other occupational demands can have a great impact on the family life of teachers as well as on their learners.

Even though the experience of stress is personal and is mediated by the personal assessment of a situation by the individual, there are on the other hand a number of practical factors that can be identified as potential causes of work-related stress. The Health Safety Executive (HSE) has identified six categories of potential stressors, which can be linked to the situation of the teachers in high schools. These six categories of potential stressors are: undue demands from the public, lack of control over work or events, the nature of relationships that one has with superiors, the way in which change is introduced, managed and communicated to staff, lack of clarity of the roles within the organisation and lack of support and job training.

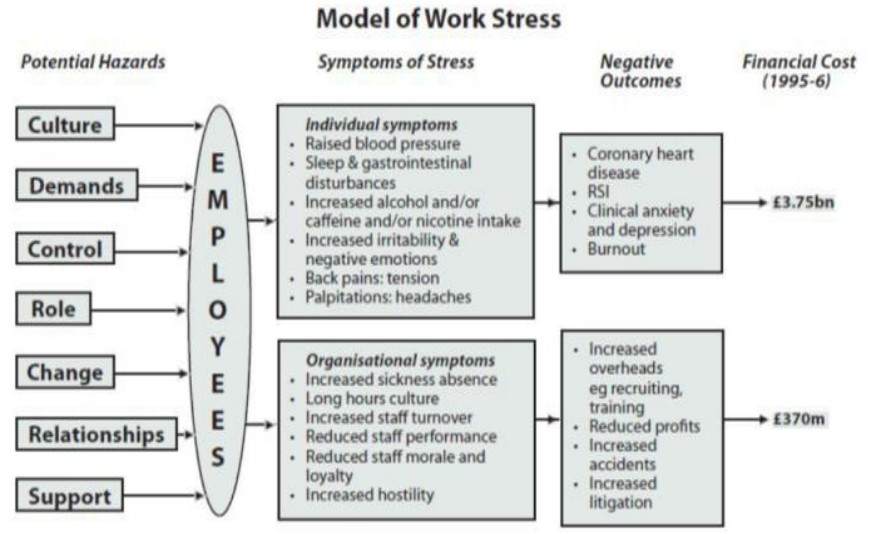

Figure 1: presents a model of work-related stress symptoms and the impact it has on the health of employees.

\section{Model of work-related stress: Source: Palmer \& Cooper (2001)}

The above stress model can be linked to the impact of workrelated stress on the health of employees. Work related stress manifests itself in a number of ways such as; physiologically, cognitively, emotionally, and behaviourally. As pointed out stress is an integral part of the life of a professional high school teacher. Teachers often encounter stressful situations in their daily work, and these stressors have cumulative effects on their lives, family as well as on the performance of their learners (Maynard \& Maynard, 2010). As a matter of fact, every person is subjected to stress and teachers are no exception, hence the need for the examination of the impact of this on the learners.

\section{Research Design}

Research design is a framework or a blueprint for conducting research (Babbie \& Mouton, 2001).). In order to have an indepth understanding of the impact of work stress of teachers on the performance of learners in high schools, the study adopted a mixed research approach. According to Bell, Bryman, and Harle (2019), a mixed method approach adds value to the understanding of a concept compared to purely qualitative or quantitative approaches. 
According to Creswell (2007) a mixed method approach implements quantitative and qualitative strands during the same phase of the research process, prioritising the methods equally and keeping the strands independent during analysis and then combining the results during the overall interpretation.

\subsection{Target Population}

The population for this study was all the high school teachers and learners in the Khomas region in Namibia

\subsection{Sample Size and Sample Size Determination}

A simple random sampling technique was used to select the sample. The sample size for this study was 100 teachers and 200 grade 11 and 12 learners.

\subsection{Research Instrument}

There is a positive correlation between the health state of an employee and productivity of that employee, and in order to fully capture the impact of the work stress of teachers on the performance of high school learners, two data collection instruments were developed. A structured questionnaire comprising of dimensions and behaviours that represent stress such as body pains, loss of interest in work, loss of appetite, restlessness, loss of sleep, not meeting deadlines, outbursts, negative attitude towards colleagues and learners was developed to collect quantitative data. A structured questionnaire was appropriate for quantitative data collection because it inquired about provision of computable opinions and information about the impact of stress of teachers on the performance of learners.

An interview guide comprising of questions that captured details of teacher-leaner interaction was used to collect qualitative data. Semi structured interviews were used for qualitative data collection because of its ability to expose hidden feelings, behaviours and attitudes in the respondents. Interviews and panel discussions were held with teachers. These allowed the teachers to express their views on the impact of stress on the performance of learners.

\subsection{Data Analysis}

Quantitative data was analysed using SPSS, while the qualitative data was analysed using thematic data analysis. Key themes emerging from the panel discussion and interviews were grouped and analysed, to extract the impact of stress of teachers on the performance of learners.

\section{Results}

The findings from the study revealed that when a teacher is stressed feels weary, exhausted, drained and tired. The findings further revealed that such stressed teachers have troubles with sleeping and show other physical symptoms such as stomach upsets or even panic attacks in addition to mysterious muscle tensions and headaches which has a huge impact on their work with students in class as this result in them missing classes or not being active in class.

Table 1: presents the symptoms of stress amongst teachers

\begin{tabular}{|l|l|l|}
\hline Insomnia & Suicidal thoughts & Temper outbusts \\
\hline Back pains & Chronic illness & Alcohol and drug abuse \\
\hline Severe headaches & Loss of memorary & Fatigue \\
\hline $\begin{array}{l}\text { Alcohol and drug } \\
\text { abuse }\end{array}$ & Loss of sex drive & \\
\hline
\end{tabular}

The results revealed the lack of resources such as books and other teaching related materials, heavy workload, and poor remuneration, as the most common sources of work stress amongst higher school teachers. These teachers further pointed out that work stress lead many of them to resort to excessive alcohol intake.

The study further revealed that as a result of work stress many of them have heart problems, persistent headache; disturbed sleep, dizziness, back pain, elevated blood pressure, exhaustion, stomach-ache, suicidal thoughts, negative thoughts, lacking the confidence and temper outburst all of which have a negative effect on the way they relate amongst themselves as well as with their learners. These respondents indicated that all these lead to unhealthy working environment whereby they end up feeling demotivated and going to class for the sake of fulfilling their daily duties and not as a duty they perform with pride and commitment to ensure that learners perform well.

\subsection{The Key Causes of Stress amongst Teachers and its Impact}

Lack of Resources: Results from the study revealed that lack of resources in schools that would enable teachers to carry out their work with efficiency and effectiveness leave them frustrated and helpless. Most teachers were leaving the teaching profession either by resigning to go for greener pastures in the private schools or outside the teaching profession, death or being discharged on conditions of ill health, while the workload continue to increase resulting in lack of human resources in schools to carter for the needs of learners. This makes it challenging for those teachers remaining who have to adjust to the arduous working environment resulting in them being stressed even more.

Heavy Workload: Results from the study revealed that the volume of work that teachers have to accomplish through the day which include responsibilities such as teaching, marking, administrative work, disciplining learners amongst other things is such a great burden to bear. The respondents further revealed that the workload keep on increasing due to the lack of personnel as most schools are understaffed and this leads to work overload and stress. The study revealed that this has a negative impact on the quality of work that these stressed teachers perform as the heavy workload lead to exhaustion. Due to the lack of personnel in these schools, teachers are handling large classes which is compromising on the quality of work that these teachers give to the learners. The teachers lamented that 
monitoring and evaluation of the performance of learners is compromised as a result.

Unreasonable Demands from Parents: The study revealed that pressure coming from the unreasonable demands from parents put a lot of stress on the teachers. Some parents do not want to take any responsible over their kids and feel that because they are paying school fees then the school has to do everything for the kids. Poor discipline and poor performance are often squarely put on the teachers and not on the upbringing of the child leaving the teachers helpless and frustrated.

\section{Lack of Consultation and Engagement in Key Decision}

Making: The findings from the study revealed that lack of participation in the decisions that affect the lives and work environment of the teachers is another cause of stress for teachers. This lack of participation by teachers in the key decision making might be attributed to the bureaucratic structures that the ministry of education follows. Often teachers are just informed and instructed to implement the new proposed policies as directed by the ministry, in some cases with no workshops nor proper training about the new developments. This leaves teachers helpless and frustrated as they are forced to implement what they do not understand or agree with.

\section{Discussion}

The findings from the study point that work stress of teachers has a huge impact on the performance of learners in high schools. Stressed teachers are often absent from work as a result of sicknesses and low morale resulting in missing classes in which case the learners are left idle. At the end of the academic year such teachers will have missed a lot of working days through sick leave, as a result they are not able to cover all the topics and materials as expected. These findings are supported by Dessler (2000) who states that for organisations work stress consequences included a decrease in the quantity and quality of job performance, increased absence and turnover, increased grievances and health care costs. However, the aforementioned author further note that work stress is not necessarily dysfunctional because some individuals work well only when under a slight stress and that at times some individuals are more productive when a deadline approaches.

The findings from the study also pointed that teachers suffers from the long working hours as their work does not end with the end of classes. Managing large classes as result of lack of personnel in most schools means long working hours, marking assignments and other tasks of learners. This leads to exhaustion which compromises the quality of grading of these tasks. According to Davey, Obst and Sheehan, (2001), long working hours is greatly prognostic of work stress. Naik, (2012; Tyagi \& Dhar, 2014) assert that work overload and long working hours are sources of work stress amongst workers and this has a huge impact on the quality of work and its outcomes. When quality of the work of learners is compromised, learners move on to the next grade before they fully master the work of that grade resulting in weaker learners moving up the grades which compromises the entire education system.

The study further found that the lack of resources in schools puts a lot of pressure on teachers as they are expected to do more with less. This leads to exhaustion and cancellation of classes on regular basis which result in either more learners failing, or the quality of their grades being compromised. These findings are supported by Long (2006) who points that when a person is stressed, he/she feels weary, exhausted, drained and tired. The aforementioned author further states that stressed people might have trouble sleeping and show other physical symptoms such as stomach upsets or even panic attacks in addition to mysterious muscle tensions and headaches. All these lead to either absent from work or poor performance on tasks given to them. Most of the learners in high schools have not mastered the art and discipline of working on their own when their teachers are absent, this means that when the teacher is absent that time is wasted and can hardly be recovered, resulting in more learners failing.

\section{Recommendations}

Based on the key findings presented above the study recommends that schools through the department of education should put in place emotion- focused programs to assist teachers whenever they show signs of being overworked or of being stressed.

Workshops and seminars should be organised regularly in schools to introduce and remind teachers about the skills and importance of relaxation and introduce programs that will increase self-confidence and motivation of teachers. Programs that will make teachers see value in what they do.

\subsection{Limitation of the Study}

The main limitation of the study was that some teachers were not so open in discussing the challenges that they are facing and stressing them as they considered such a discussion as being too personal and exposing them as weak professionals. However, efforts were made to create a conducive environment that allowed them to open up to the discussion and they provided vital information which allowed the researcher to comprehensively address the problem under investigation.

\section{Conclusion}

Avoidance of work-related stress is an important responsibility of an organisation. This should include a process which encompasses the spotting of signs of work-related stress and taking introductory actions, scrutinising risk factors and risk groups, planning an action, applying the action plan and weighing the interventions. A stress teacher is a danger to the learners and every effort should be made to address the issues of stress in the schools and the consequences of such stress are so costly to the learners as the society as a whole.

\section{References}

- Albrecht K. (1988). Stress and well-being. Its causes and consequences for performance.

- Journal of Applied psychology, 55, (2), 494-497.

- Albrecht, K., (2010). Stress and the Manager. New York: Simon and Schuster Business and Economics.

- Babbie, E., \& Mouton, J. (2001). The Practice of Social Research. South African Edition. Cape Town:

- Bowin, R.B \& Harvey, D. (2001). Human Resource Management an experiential approach. (2nd ed.). New Jersey: Prentice Hall. 
- Cooper, C. L. \& Cartwright, S. (1994). Healthy Mind; Healthy Organisation. A Proactive Approach to Occupational Stress, Journal of Human Relations, 47(1): 455-71. Crossref

- Cooper, C. L. \& Payne, R., (2008). Causes, Coping and Consequences of Stress at Work . New York: Wiley.

- Creswell. J. W. (2007). Qualitative inquiry and Research design: Choosing among five approaches (3rd ed.). Thousand Oaks, CA: Sage.

- Davey, J.D., Obst, P.L. \& Sheehan, M.C. (2001), "Demographic and workplace characteristicswhich add to the prediction of stress and job satisfaction within the police workplace", Journal of Police and Criminal Psychology, Vol. 16 No. 1, pp. 29-39. Crossref

- HSE (Health and Safety Executive). (2002). Health and Safety Statistics Highlights 2001/2002.

- [Online] Availableat: www.hse.gov.uk/ statistics/overpic.htm. (Accessed: 10 June 2016).

- HSE, (2011). A business case for the Management Standards for Stress, HSE Books.

- Long, B. C. (2006). Aerobic Conditioning and Stress Inoculation: A Comparison of Stress Management Interventions. Cognitive Therapy and Research, 8, 517-542. Crossref

- Maynard, E.P., \& Maynard, N.E. (2010). "Stress in Police Families: Some Policy Implications", Journal of Police Science and Administration, 10, (I.3):302-314.

- Naik, K.D. (2012). An analytical study of Job Stress of the Police Personnel at Waghodiya Police Station in Vadodara City. Paper presented at Ninth AIMS International Conference on Management (1-4 January 2012) FLAME, Pune, India. http://shodhganga.inflibnet.ac.in/bitstream/10603/21078/15 /16_bibliography.pdf (Retrieved: 14 November 2016)

- Ornelas, S. \& Kleiner, B. H. (2003). New Development in Managing Job Related Stress, Journal of Equal Opportunities International, 2(5): 64-70. Crossref

- Palmer S, Cooper C, Thomas K (2001). Model of organisational stress for use within an occupational health education/promotion or wellbeing programme - A short communication. Health Education Journal, 60(4), 378-380. Crossref

- Rees, C. J. \& Redfern, D. (2000), Recognizing the Perceived Causes of Stress. A Training and Development Perspective, Journal of Industrial and Commercial Training, 32(4): 120127. Crossref

- Robins, S. P. (2001). Organisational Behaviour. (9t h ed.). Cape Town: Prentice Hall.

- Tehrani, N. (2002). Managing Organisational Stress, CIPD. Retrieved on June 16, 2014, from www.cipd.co.uk

- Van Heerden, E. (2005). Life Skills. My Journey, My Destiney (5t h ed.). Cape Town: Prentice Hall.
- Varca, P. E. (1999). Work Stress and Customer Service Delivery: Journal of Services Marketing, 13(3): 229-241. Crossref 